\title{
Functional disability and health-related quality of life in juvenile idiopathic arthritis children from Beni-Suef
}

\author{
Enas A. Abdelaleem ${ }^{1 *} \mathbb{D}$, Dina A. Ezzat ${ }^{2}$ and Gehad R. Mostafa ${ }^{3}$
}

\begin{abstract}
Background: Juvenile idiopathic arthritis (JIA) is a common childhood disease which causes significant impairment in quality of life. The aim of the study is to assess the health-related quality of life and its relation to functional disability in JIA patients.

Child health assessment questionnaire (CHAQ) and pediatrics quality of life 4 generic core questionnaire (PedsQL) were used to evaluate functional disability and health-related quality of life.

Results: CHAQ (VAS) of JIA patients ranged from 0 to 9 with a mean of $3.64 \pm 2.9$ (SD), and of controls ranged from 0 to 4 with a mean of $1.32 \pm 1.3$ (SD) with a statistically significant difference and a $p$ value of 0.001 . CHAQdisability index (DI) of the cases ranged from 0 to 3 with a mean of $1.06 \pm 0.9$ (SD) and of controls was consistent $=0$. Pediatric quality of life (PedsQL) among cases ranged from 26.08 to 91.3 with a mean of $67.95 \pm 19.2$ (SD) and among controls ranged from 78.27 to 100 with a mean of $90.73 \pm 7.7$ (SD) showing statistically significant difference with a $p$ value $<0.001$.

Childhood health assessment questionnaire (CHAQ) scores were significantly higher among studied females with JIA as compared with males. The mean CHAQ-DI scores were $4.56 \pm 2.7 \mathrm{vs.} 1.29 \pm 2.6$ in females and males respectively with a significant $p$ value of 0.002 . The mean CHAQ-(VAS) scores were $1.38 \pm 0.8$ vs. $0.23 \pm 0.3$ in females and males respectively with a significant $p$ value of 0.016 . Pediatric quality of life (PedsQL) scores were significantly higher among studied males with JIA as compared with studied females. The childhood health assessment questionnaire (CHAQ) was negatively correlated with all (physical, emotional, social, and school) items of the pediatric quality of life (PedsQL) $(p<0.001)$.

Conclusion: We found a significant impairment in the functional ability and health-related quality of life in patients with JIA compared to healthy children, with more impairment in females than males. CHAQ was negatively correlated with all items of PedsQL.
\end{abstract}

Keywords: JIA, CHAQ, PedsQL

\footnotetext{
* Correspondence: dr.enas2000@gmail.com

${ }^{1}$ Rheumatology and Rehabilitation Department, Faculty of Medicine,

Beni-Suef University, Beni-Suef, Egypt

Full list of author information is available at the end of the article
}

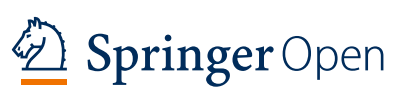

(ㅇ The Author(s). 2021 Open Access This article is licensed under a Creative Commons Attribution 4.0 International License, which permits use, sharing, adaptation, distribution and reproduction in any medium or format, as long as you give appropriate credit to the original author(s) and the source, provide a link to the Creative Commons licence, and indicate if changes were made. The images or other third party material in this article are included in the article's Creative Commons licence, unless indicated otherwise in a credit line to the material. If material is not included in the article's Creative Commons licence and your intended use is not permitted by statutory regulation or exceeds the permitted use, you will need to obtain permission directly from the copyright holder. To view a copy of this licence, visit http://creativecommons.org/licenses/by/4.0/. 


\section{Background}

Juvenile idiopathic arthritis (JIA) is a common childhood disease characterized by persistent joint inflammation [1]. The estimated prevalence of JIA ranges from 16 to 150 persons per 100,000 [2]. JIA is diagnosed in children aged below 16 years and have persistent arthritis for at least 6 weeks. The etiology of JIA is still unknown, but possible genetic and environmental factors are associated [3].

Juvenile idiopathic arthritis mostly results in significant disabilities such as chronic pain, decreased range of joint mobility, joint deformities, growth disturbances, and impaired physical functions. This is of concern because physical condition during childhood and early adulthood results in many short- and long-term health impairments [4].

In addition, the functional abilities of juvenile idiopathic arthritis patients have been reported to be lower than those of normal children [5]. Functional ability is therefore an important issue in the management of juvenile idiopathic arthritis, and its assessment helps to evaluate a patient's current state and also the efficacy of treatment [6].

Many studies have confirmed that the health-related quality of life of children with juvenile idiopathic arthritis is bad when compared to that of healthy children [7]. About 20\% of juvenile idiopathic arthritis patients have behavioral problems, communication impairment, depressive mood, and agitation [8].

However, although the great association between chronic pain and health-related quality of life has been critical for many researches, few studies have focused on the relation between functional ability and quality of life in children with juvenile idiopathic arthritis [9].

The assessment of the health and functional status of children with JIA can be done by using various tools but the childhood health assessment questionnaire (CHAQ) is considered to be the most valuable $[10,11]$. VAS is used to assess current pain degree [12].

The PedsQL ${ }^{\mathrm{TM}}$ measurement model was designed to measure pediatric health-related quality of life. The PedsQL $^{\mathrm{TM}} 4.0$ generic core scales have been translated into over 60 languages and data were published on over 25,000 children and adolescents in more than 75 journals since 2001 for healthy children and many childhood chronic health problems [13].

The aim of the present study is to assess JIA patients' health-related quality of life and compare it with a healthy age-matched population, and to detect the relation between functional ability and quality of life among juvenile idiopathic arthritis patients.

\section{Methods}

\section{Patients}

Twenty-five patients with established JIA participated in the study.
"Inclusion criteria were as follows:

Age 6-16 years

A diagnosis of JIA according to ILAR [14]

The ability to move without assistance, understand and obey instructions in study tests

*Exclusion criteria were as follows:

Children with neurological diseases

Children with any chronic disease that impair mentality or ability to participate in the study

Age younger than 6 years due to difficulties in understanding questions and obeying orders

\section{Controls}

Twenty-five normal children visiting our hospital.

*Verbal consent has been obtained from the parents to participate in the study after being given an explanation of content (we could not obtain written consent as most of them were illiterates). The study was approved by the ethical committee. The reference number is FMBSUREC/08012019.

\section{Assessment}

All participants included in this study were subjected to complete history taking, thorough clinical examination, routine laboratory and serological investigations, body mass index (BMI) calculation, child health assessment questionnaire (CHAQ) [11], pediatrics quality of life 4 generic core questionnaire (PedsQL v4) [15], and measurement of pain degree on a $10-\mathrm{cm}$ visual analog scale (VAS).

C-HAQ has 30 categories summated into 8 groups of physical function, dressing and grooming (4 items), arising ( 2 items), eating ( 3 items), walking ( 2 items), hygiene (5 items), reach (4 items), grip (5 items), and activities (5 items). The original C-HAQ DI is scored on a 4-point scale which measures the degree of difficulty a child has in accomplishing each task during the last week (0 without any difficulty, 1 with some difficulty, 2 with much difficulty, and 3 unable to do). The resultant marks are considered not applicable if the task is beyond the child's developmental age, and the respondent indicates if assistance or aids/devices were needed for any mission [11]. The discomfort index (pain) and health status index (general health status) each include a single item, a 10-cm visual analog scale (VAS) [12].

The PedsQL ${ }^{\mathrm{Tm}}$ measurement model was used to measure pediatric health-related quality of life with lower scores indicating worse HRQoL. The PedsQL ${ }^{\mathrm{\tau}} 4$ generic version assesses physical, emotional, social, and school functioning domains throughout the last month. Items are scored as 0 points for "no problem at all," 1 point for 
"almost no problem," 2 points for "problem sometimes," 3 points for "problems often," and 4 points for "problems almost always." Each question's point value is converted to a corresponding score on a $0-100$ point scale, with scores of $1,2,3$, and 4 points corresponding to scores of $75,50,25$, and 0 points, respectively [15].

An Arabic version of CHAQ was used according to El Miedany et al. [16]. We translated the English version of PedsQL v4 into Arabic to be comprehended by patients and their parents.

\section{Statistical analysis}

- The data were collected, coded then entered, and analyzed using the SPSS version 22 (statistical package for social science).

- Descriptive statistics was done for categorical variables by frequency and percentage, and for numerical variables in the form of mean and standard deviation (mean $\pm \mathrm{SD}$ ).

- Suitable statistical tests of significance were used.

- $P$ values equal to or less than 0.05 were considered statistically significant.

- Simple graphs were used to illustrate some information.

\section{Results}

Age of the JIA patients ranged from 7 to 16 years with a mean of $11.48 \pm 2.9$ years and age of controls was 8 to 16 years with the mean of $11.68 \pm 2.8$ years with no statistically significant difference $(p$ value $=0.808)$. Seventy-two percent of the JIA cases were females and $28 \%$ were males, fifty-six \% of the controls were females and $44 \%$ were males with no statistically significant difference.

Patients' weight ranged from 22 to $63 \mathrm{~kg}$ with a mean of $38.86 \pm 10.9$ (SD) $\mathrm{kg}$ and controls weight ranged from 25.5 to $59 \mathrm{~kg}$ with a mean of $40.26 \pm 10.6 \mathrm{~kg}$ (SD) with no statistically significant difference $(p$ value $=0.649$ ) Patients had significantly shorter stature as compared with healthy control subjects where their mean height was $127.08 \pm 18.9 \mathrm{~cm}$ vs. $142.78 \pm 12.4 \mathrm{~cm}$ in controls $(p$ $=0.001)$. Patients had significantly higher BMI as compared with healthy control where mean BMI was 24.25 \pm 5.5 vs. $19.41 \pm 2.7$ in JIA cases vs. controls respectively $(p=0.001)$.

Oligoarticular type was the most predominant among the studied JIA patients presenting $60 \%$ of them, $28 \%$ were polyarticular, and $12 \%$ were systemic onset. Uveitis was present in one female patient with oligoarticular type. Four patients had joint deformities of the knee and hand joints.

WBCs of JIA patients ranged from 3.46 to 11.20 with a mean of $7.35 \pm 1.9(\mathrm{SD})$, RBCs ranged from 3.26 to 5.50 with a mean of $4.53 \pm 0.7$ (SD), PLTs ranged from 174 to 454 with a mean of $315.36 \pm 85.3$ (SD), also ESR ranged from 12 to 135 with a mean of $24.96 \pm 31.3$ (SD), and CRP ranged from 0 to 96 with a mean of $25.76 \pm$ 29.0 (SD). Rheumatoid factor was positive in two patients with polyarticular subtype. ANA was positive in $40 \%$ of cases and negative in $60 \%$ of cases and CRP was positive in $96 \%$ of cases and negative in $4 \%$ of cases. All our patients were on non-biologic DMARDs \pm NSAIDs for control of their disease. Thirteen patients were on irregular use of steroids with a dose ranged from 5 to $10 \mathrm{mg} /$ day.

CHAQ (VAS) was statistically significantly higher in patients than controls (Table 1). CHAQ scores were significantly higher among studied females with JIA as compared with males. The mean CHAQ-DI scores were $4.56 \pm 2.7$ vs. $1.29 \pm 2.6$ in females and males respectively with a significant $p$ value of 0.002 . The mean CHAQ-VAS scores were $(1.38 \pm 0.8$ vs. $0.23 \pm 0.3)$ in females and males respectively with a significant $p$ value of 0.016 .

Patients with polyarticular disease had the highest CHAQ (VAS) followed by the oligoarticular subtype then the systemic onset group but with no statistical significance $(p=0.853)$. CHAQ (DI) was highest in the oligoarticular group then the systemic onset and the polyarticular group but again with no statistical significance $(p=0.905)$.

Pediatric quality of life (PedsQL) was statistically lower in patients than in controls (Table 2). PedsQL scores were significantly higher among studied males with JIA as compared with studied females where the mean scores were $82.45 \pm 9.1$ vs. $62.32 \pm 19.3$ in males and females respectively with a $p$ value of 0.015 .The same result was reported regarding the physical item of PedsQL; where the mean scores were $84.82 \pm 14.0$ vs. $55.90 \pm 26.9$ in males and females respectively with a $p$ value of 0.013 . Studied males with JIA had higher scores regarding emotional, social, and school items of PedsQL

Table 1 Childhood health assessment questionnaire (CHAQ) score among studied population ( $N=50)$

\begin{tabular}{llll}
\hline & Cases $\boldsymbol{N}=\mathbf{2 5}$ & Controls $\boldsymbol{N}=\mathbf{2 5}$ & $\boldsymbol{p}$ value \\
\hline CHAQ (VAS) & & & \\
Mean \pm SD & $3.64 \pm 2.9$ & $1.32 \pm 1.3$ & $0.001^{*}$ \\
Range & $0-9$ & $0-4$ & \\
CHAQ (DI) & & & \\
Mean \pm SD & $1.06 \pm 0.9$ & 0 & \\
Range & $0-3$ & 0 &
\end{tabular}

CHAQ Childhood Health Assessment Questionnaire, VAS Visual Analog Scale, DI Disability Index

${ }^{*} p$ value 0.05 is considered significant by Mann Whitney $U$ test CHAQ-DI was consistent $=0$ with all studied controls 
Table 2 Pediatric quality of life inventory 4.0 generic core scales (PedsQL) among studied population $(N=50)$

\begin{tabular}{|c|c|c|c|}
\hline & Cases $N=25$ & Controls $N=25$ & $p$ value \\
\hline \multicolumn{4}{|l|}{ Peds QL } \\
\hline Mean \pm SD & $67.95 \pm 19.2$ & $90.73 \pm 7.7$ & $<0.001^{*}$ \\
\hline Range & 26.08-91.30 & $78.27-100.0$ & \\
\hline \multicolumn{4}{|l|}{ Peds QL(p) } \\
\hline Mean \pm SD & $63.99 \pm 27.1$ & $90.37 \pm 7.6$ & $<0.001 *$ \\
\hline Range & $12.5-100.0$ & $78.13-100.0$ & \\
\hline \multicolumn{4}{|l|}{ Peds QL(e) } \\
\hline Mean \pm SD & $67.00 \pm 22.2$ & $93.60 \pm 8.7$ & $<0.001 *$ \\
\hline Range & $35-100$ & 70-100 & \\
\hline \multicolumn{4}{|l|}{ Peds QL(s) } \\
\hline Mean \pm SD & $78.20 \pm 24.1$ & $92.40 \pm 9.5$ & $0.008^{*}$ \\
\hline Range & $15-100$ & $70-100$ & \\
\hline \multicolumn{4}{|l|}{ Peds QL (sc) } \\
\hline Mean \pm SD & $65.40 \pm 19.7$ & $86.80 \pm 12.8$ & $<0.001 *$ \\
\hline Range & $65.40 \pm 19.7$ & 70-100 & \\
\hline
\end{tabular}

${ }^{*} p$ value $\leq 0.05$ is considered significant by Mann Whitney $U$ test

Peds QL pediatric quality of life, $p$ physical, $e$ emotional, $s$ social, $s c$ school

as compared with studied females but without statistically significant differences where $p$ values were $>0.05$.

Polyarticular group had the lowest PedsQL followed by the oligoarticular then the systemic onset group but with no statistical significance $(p=0.566)$.
CHAQ-DI was positively correlated with BMI where $r=0.520, p$ value $=0.001$. Also, CHAQ-VAS was positively correlated with BMI where $r=0.365, p$ value $=0.009$ and with ESR where $r=0.460, p$ value $=0.021$. However, no detected correlation with CHAQ-DI or CHAQ-VAS and other studied parameters (e.g., age, weight, height, and routine labs), where $p$ values $>0.05$. The pediatric quality of life (PedsQL) was not correlated with any of the studied parameters where $p$ values $>0.05$.

The childhood health assessment questionnaire (CHAQ) was negatively correlated with all (physical, emotional, social, and school) items of the pediatric quality of life (PedsQL) $(p<0.001)$ (Fig. 1).

\section{Discussion}

Patients with juvenile idiopathic arthritis (JIA) experience physical, communicational, and psychological problems that impair their quality of life. Health-related quality of life (HRQoL) is a complex construct including those items and other effects of disease on well-being. Many studies found that JIA patients have lower HRQoL compared to healthy individuals [17].

This study was done to assess JIA patients' healthrelated quality of life and to compare it with a healthy age-matched volunteer, and to detect relation between functional ability and quality of life in JIA patients.

Seventy-two percent of our JIA cases were females and $28 \%$ were males. El-Banna et al. found a female:male

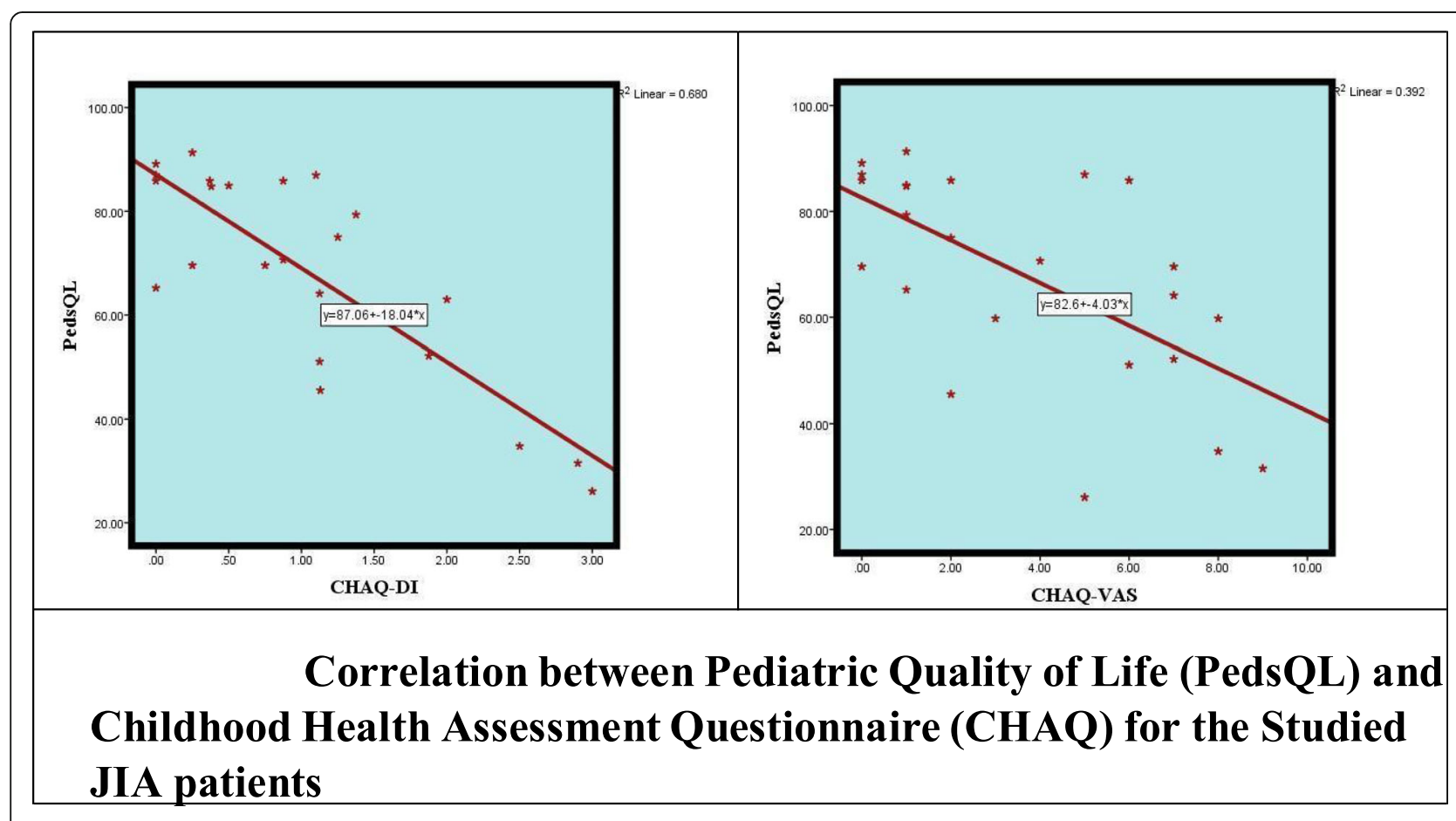

Fig. 1 Correlation between Pediatric Quality of Life (PedsQL) and Childhood Health Assessment Questionnaire (CHAQ) for the Studied JIA patients 
ratio of 3:2 [18]. Classification of our JIA patients subtypes was in accordance with Ebraheem et al. [19]. Their patients were 25 oligoarticular (45.45\%), 15 polyarticular (27.27\%), and 15 systemic-onset patient (27.27\%) [19]. El-Najjar et al. found that oligoarticular subtype accounts for about $50 \%$ of cases [20].

Our results showed also that CHAQ (VAS) of JIA patients was significantly higher than controls ( $p$ value of 0.001). In agreement with our results, Amine et al. found that the mean CHAQ of JIA patients was $0.84 \pm 0.71$ and ranged from 0 to 2.87. And the mean CHAQ (VAS) was $35.44 \pm 22.23$ and ranged from 0 to 80 [21]. Also, Tarakci et al. (2011) found that mean CHAQ of JIA patients was $0.28 \pm 0.24$. The JIA group had significantly higher CHAQ score $(p=0.000)$ compared with the control group [22].

Pediatric quality of life (PedsQL) among cases ranged from 26.08 to 91.3 with a mean of $67.95 \pm 19.2$ (SD) and among controls ranged from 78.27 to 100 with a mean of $90.73 \pm 7.7$ (SD) showing statistically significant difference with a $p$ value $<0.001$. The physical, emotional, social, and school items of the PedsQL was significantly lower in patients than controls with a $p$ value $<0.001$.

In agreement with our results, Lundberg et al. found that children with JIA had lower physical, psychosocial, and total PedsQL $(p<0.001)$ [23].

Mańczak et al. found that the QoL of JIA patients was lower than in healthy children in items of physical health, mood and emotions, autonomy, and social support $(p<0.001)$. The QoL of JIA patients compared with the QoL of children from the Polish reference group was lower only in items of physical health $(p<$ $0.001)$, whereas it was higher in terms of psychological well-being ( $p=0.023)$, parent relations, and social life ( $p$ $=0.005)$ and financial resources $(p<0.001)$. In most terms, the evaluation done by the parents was lower than the child's [24].

Childhood health assessment questionnaire (CHAQ) scores were significantly higher among our JIA females as compared with males.

Pediatric quality of life (PedsQL) scores were significantly lower among studied females with JIA as compared with studied males where the mean scores were $82.45 \pm 9.1$ vs. $62.32 \pm 19.3$ in males and females respectively with a $p$ value of 0.015 . The same result was reported regarding the physical item of PedsQL $(p)$; where the mean scores were $84.82 \pm 14.0$ vs. $55.90 \pm$ 26.9 in males and females respectively with a $p$ value of 0.013 . Studied males with JIA had higher scores regarding emotional, social, and school items of PedsQL as compared with studied females but without statistically significant differences where $p$ values were $>0.05$. These differences may be explained by social and cultural issues in which the family especially in rural areas gives more psychological and financial support for male patients more than females. They may be explained also by hormonal factors even in this young age.

Previous studies have detected that PedsQL scores in JIA patients were significantly lower than healthy individuals. These differences may be higher in older children and children with polyarticular subtype [17]. JIA has significant impact on HRQoL. Males had slightly higher scores than females in both physical and psychosocial items [25].

No statistically significant differences were found in our study between subtypes of JIA patients according to CHAQ or PedsQL. Ebraheem et al. found significant difference between JIA subtypes according to CHAQ ( $p$ $=0.02)$ and PedsQL $(p=0.03)$ [19].

In our study, CHAQ-VAS was positively correlated with BMI where $r=0.365, p$ value $=0.009$ and with $\mathrm{ESR}$ where $\mathrm{r}=0.460, p$ value $=0.021$. CHAQ-DI was positively correlated with BMI where $r=0.520, p$ value $=$ 0.001 , but did not correlate well with ESR, which is comparable with the findings of previous studies [26, 27]. ESR alone might not be a good indicator for functional impairment in JIA patients. ESR may be elevated due to systemic inflammation other than arthritis. Thus, patients may have less impairment in functional abilities in spite of the high ESR especially in patients with systemic-onset subtype whereas patients with oligoarticular type can have near-normal ESR in spite of active joints.

The pediatric quality of life (PedsQL) was not correlated with any of the studied parameters where $p$ values $>0.05$. The childhood health assessment questionnaire (CHAQ) was significantly negatively correlated with all (physical, emotional, social, and school) items of the pediatric quality of life (PedsQL).

Sawyer et al. found a significant negative correlation between the pain intensity score and the PedsQL physical functioning, emotional well-being, social functioning, and treatment scale scores $[28,29]$.

Gueddari et al. found a significant correlation between CHAQ and the number of active joints $(r=0.39, p=$ $0.006)$ and pain $(r=0.45, p<0.01)$. However, they found no associations between disease duration, disease activity, and physical ability [30].

Kwon et al. found negative correlations between functional ability scores and each item of healthrelated quality of life. CHAQ-DI scores decreased when scores of the physical $(r=-0.709, p<0.01)$, emotional $(r=-0.519, p<0.01)$, social $(r=-0.623$, $p<0.01)$, and school $(r=-0.466, p<0.05)$ subscales as well as the health-related quality of life score $(r=$ $-0.736, p<0.01)$ increased [2].

There were negative significant correlations between age and HRQoL scale scores. Statistically significant 
differences in physical health, total score (PedsQL 4.0), daily activities, and worry (PedsQL 3.0) were detected by lower scores of children with polyarticular JIA. These differences appeared independent of age and gender [17]. Watchareewan et al. found that CHAQ-DI had a good correlation with disease activity during disease activity but a poor correlation during inactive disease. Therefore, CHAQ is mainly valuable for assessing functional ability during active disease [31].

There were some limitations to our study. The small sample of the patients and consequently the small size for each JIA subtype. Therefore, larger, multicenter studies are suggested in the future to study functional ability and health-related quality of life in JIA patients.

\section{Conclusion}

We found a significant impairment in the functional ability and health-related quality of life in patients with JIA compared to healthy children, with more impairment in females than males. CHAQ was negatively correlated with all items of PedsQL.

We recommend using CHAQ and PedsQL in regular follow-up of JIA patients. And we recommend making further studies on large number of JIA patients. Clinical follow-up and developmental programs should also concentrate on physical performance and functional ability improvement in children with JIA.

\begin{abstract}
Abbreviations
ACR: The American College of Rheumatology; BMI: Body mass index; CHAQ: Child health assessment questionnaire; DI: The disability index; ESR: Erythrocyte sedimentation rate; HRQOL: Health-related quality-of-life; ILAR: International League of Associations for Rheumatology; JA: Juvenile idiopathic arthritis; PedsQL: Pediatrics quality of life inventory 4.0;

SD: Standard deviation; VAS: Visual analog scale
\end{abstract}

\section{Acknowledgements}

To all the patients, their parents, and control.

\begin{abstract}
Authors' contributions
EA is the corresponding author and was involved in analyzing the data, writing the manuscript. DE participated in examination of the patients involved in assessing the patients, collecting, and analyzing data. GR collected the data from the patients and control, performed the examination, and was involved in assessing the patients. All authors have read and approved the manuscript.
\end{abstract}

\section{Funding}

Not applicable.

\section{Availability of data and materials}

The datasets used and/or analyzed during the current study are available from the corresponding author on reasonable request.

\section{Ethics approval and consent to participate}

Verbal consent was obtained from parents of the JIA children and controls (as most of them were illiterates) and were approved by the ethical committee of the Faculty of Medicine, Beni-Suef University. The reference number is FMBSUREC/08012019/Gehad Ramadan.

\section{Consent for publication}

All participants and/or their parents have approved the publication of the manuscript.

\section{Competing interests}

The authors declare that they have no competing interests.

\section{Author details}

${ }^{1}$ Rheumatology and Rehabilitation Department, Faculty of Medicine, Beni-Suef University, Beni-Suef, Egypt. ${ }^{2}$ Pediatric Department, Faculty of Medicine, Beni-Suef University, Beni-Suef, Egypt. ${ }^{3}$ Rheumatology and Rehabilitation Department, Beni-Suef General Hospital, Beni-Suef, Egypt.

Received: 19 November 2020 Accepted: 15 January 2021

Published online: 17 February 2021

\section{References}

1. Eng SW, Aeschlimann FA, van Veenendaal M, Berard RA, Rosenberg AM (2019) Patterns of joint involvement in juvenile idiopathic arthritis and prediction of disease course: a prospective study with multilayer nonnegative matrix factorization. PLoS Med 16(2):e100275.

2. Kwon HJ, Kim YL, Lee SM (2015) Relation between functional ability and health-related quality of life of children with juvenile rheumatoid arthritis. J Phys Ther Sci 27(3):837-840

3. Giancane G, Consolaro A, Lanni S, Davi S, Schiappapietra B, Ravelli A (2016) Juvenile idiopathic arthritis: diagnosis and treatment. Rheumatol Ther 3: 187-207

4. Stinson JN, Luca NJ, Jibb LA (2012) Assessment and management of pain in juvenile idiopathic arthritis. Pain Res Manag 17(6):391-396

5. Kwon HJ, Kim YL, Lee HS, Lee SM (2017) A study on the physical fitness of children with juvenile rheumatoid arthritis. J Phys Ther Sci 29(3):378-383

6. Ter Haar NM, van Dijkhuizen EHP, Swart JF (2019) Treatment to target using recombinant interleukin-1 receptor antagonist as first-line monotherapy in new-onset systemic juvenile idiopathic arthritis: results from a five-year follow-up study. Arthritis Rheumatol 71(7):1163-1173

7. Listing M, Mönkemöller K, Liedmann I (2018) The majority of patients with newly diagnosed juvenile idiopathic arthritis achieve a health-related quality of life that is similar to that of healthy peers: results of the German multicenter inception cohort (ICON). Arthritis Res Ther 20(1):106

8. Stevanovic D, Susic G (2013) Health-related quality of life and emotional problems in juvenile idiopathic arthritis. Qual Life Res 22(3):607-612

9. Hanns L, Cordingley L, Galloway J, loannou Y (2018) Depressive symptoms, pain and disability for adolescent patients with juvenile idiopathic arthritis: results from the Childhood Arthritis Prospective Study. Rheumatology 57(8): 1381-1389

10. Narayan K, Muthuraja M (2015) Functional health assessment of children suffering from juvenile idiopathic arthritis. Int J Contemp Pediatr 2(4): 384-388

11. Singh G, Athreya BH, Fries JF, Goldsmith DP (1994) Measurement of health status in children with juvenile rheumatoid arthritis. Arthritis Rheum 37: 1761-1769

12. Lam C, Young N, Marwaha J, McLimont M, Feldman BM (2004) Revised versions of the Childhood Health Assessment Questionnaire (CHAQ) are more sensitive and suffer less from a ceiling effect. Arthritis Rheum 51: 881-889

13. Varni JW, Burwinkle TM, Seid M (2005) The PedsQL ${ }^{\text {TM }}$ as a pediatric patientreported outcome: reliability and validity of the PedsQL ${ }^{\text {TM Measurement }}$ Model in 25,000 children. Expert Rev Pharmacoecon Outcomes Res 5(6): 705-719

14. Petty RE, Southwood TR, Manners P, Baum J, Glass DN, Goldberg J, He X (2004) International League of Associations for Rheumatology classification of juvenile Idiopathic Arthritis. J Rheumatol 31(2):390-392

15. Varni JW, Burwinkle TM, Seid M, Skarr D (2003) The PedsQL 4.0 as a pediatric population health measure: feasibility, reliability, and validity. Ambul Pediatr 3(6):329-341

16. El Miedany YM, Youssef SS, El Gaafary M (2003) Cross cultural adaptation and validation of the Arabic version of the Childhood Health Assessment Questionnaire for measuring functional status in children with juvenile idiopathic arthritis. Clin Exp Rheumatol 21:387-393

17. Lapin WB, Phillips T, Guttman-Lapin D, Brown A, Muscal E, Seeborg FO (2018) Quality of Life Assessment in Juvenile Idiopathic Arthritis: A Single Center Assessment . Arthritis Rheumatol 70 (suppl 10):2404.

18. El Banna HS, Nad DW, Hussein MA, Hablas SA, Darwish NV, Abu-Zaid MH et al (2019) Role of ultrasonography in the detection of subclinical synovitis 
in oligoarticular and polyarticular juvenile idiopathic arthritis. Egypt Rheumatol 41:151-155

19. Ebraheem MF, Sallam RA, Mohsen MA, El Kady BA, El Hwary GE, Baiomy AA (2019) Vascular cell adhesion molecule-1, flow mediated dilatation and carotid intima media thickness in children with juvenile arthritis. Egypt Rheumatol 41:145-150

20. El Najjar AR, Negm MG, El Sayed WM (2014) The relationship between depression, disease activity and physical function in juvenile idiopathic arthritis patients in Zagazig University Hospital. Egypt Rheumatol 36(3): $145-150$

21. Amine B, Rostom S, Benbouazza K, Abouqal R (2008) Health related quality of life survey about children and adolescents with juvenile idiopthic arthritis. Rheumatol Int 29(3):275-279

22. Tarakci E, Yeldan I, Kaya Mutlu E, Baydogan SN, Kasapcopur O (2011) The relationship between physical activity level, anxiety, depression, and functional ability in children and adolescents with juvenile idiopathic arthritis. Clin Rheumatol 30(11):1415-1420

23. Lundberg V, Lindh V, Errikson C, Petersen S, Eurenius C (2012) Health-related quality of life in girls and boys with juvenile idiopathic arthritis: self- and parental reports in a cross-sectional study. Peditr Rheumatol 10(1):33

24. Mańczak M, Rutkowska-Sak L, Raciborski F (2016) Health-related quality of life in children with juvenile idiopathic arthritis - child's and parent's point of view. Rheumatologia 54(5):243-250

25. Smith A, Saqib B, Lee R, Thomson W, Cordingley L (2020) What impact does JIA have on health-related quality of life over time and by gender? Rheumatology 59(2):111-134

26. Oen K, Tucker L, Huber AM, Miettunen P, Scuccimarri R, Campillo $S$ et al (2009) Predictors of early inactive disease in a juvenile idiopathic arthritis cohort: results of a Canadian multicenter, prospective inception cohort study. Arthritis Rheum 61(8):1077-1086

27. Susic GZ, Stojanovic RM, Pejnovic NN, Damjanov NS, Soldatovic II, Jablanovic DB et al (2011) Analysis of disease activity, functional disability and articular damage in patients with juvenile idiopathic arthritis: a prospective outcome study. Clin Exp Rheumatol 9(2):337-344

28. Sawyer MG, Reynolds KE, Couper JJ, French DJ, Kennedy D, Martin J et al (2004) Health-related quality of life of children and adolescents with chronic illness. Qual Life Res 13:1309-1319

29. Sawyer MG, Carbone JA, Whitham J, Roberton DM (2005) The relationship between health-related quality of life, pain, and coping strategies in juvenile arthritis. Qual Life Res 14(6):1585-1598

30. Watchareewan S, Soamarat V (2018) The correlation between the Childhood Health Assessment Questionnaire and disease activity in juvenile idiopathic arthritis. Musculoskelatal Care 16(3):339-344

31. Gueddari S, Amine B, Mohamed V, Rostom S, Mohammed V, EL Badri D (2014) Physical activity, functional ability, and disease activity in children and adolescents with juvenile idiopathic arthritis. Clin Rheumatol 33(9):1289-94.

\section{Publisher's Note}

Springer Nature remains neutral with regard to jurisdictional claims in published maps and institutional affiliations.

\section{Submit your manuscript to a SpringerOpen ${ }^{\circ}$ journal and benefit from:}

- Convenient online submission

- Rigorous peer review

- Open access: articles freely available online

- High visibility within the field

- Retaining the copyright to your article

Submit your next manuscript at $\boldsymbol{\nabla}$ springeropen.com 